\title{
MODELLING OF GLACIER AND ICE SHEET MICRO-TOPOGRAPHY BASED ON UNMANNED AERIAL VEHICLE DATA, ANTARCTICA
}

\author{
Xiaohan Yuan ${ }^{1,2}$, Gang Qiao ${ }^{1,2}$, Yanjun $\mathrm{Li}^{1,2}$, Hongwei $\mathrm{Li}^{1,2}$, Ruguo Xu ${ }^{1,2}$ \\ ${ }^{1}$ Center for Spatial Information Science and Sustainable Development, Tongji University, 1239 Siping Road, Shanghai, China \\ ${ }^{2}$ College of Surveying and Geo-Informatics, Tongji University, 1239 Siping Road, Shanghai, China
}

Commission TCIII, WG III/9

KEY WORDS: Modelling, Micro-topography, Unmanned Aerial Vehicle, RTK, SfM-MVS, East Antarctica

\begin{abstract}
:
Modelling of glacier and ice sheet micro-topography is meaningful for the understanding of interactions between local ice mass and climate. Here, we used an Unmanned Aerial Vehicle (UAV) platform composed of a DJI Phantom 4 and a D-RTK mobile station to model the surface micro-topography around Zhongshan Station of China, East Antarctica. Two UAV survey types (vertical and oblique aerial photogrammetry) were performed during the China's 35th Antarctic expedition (CHINARE) in 2018-2019. Six surveys were obtained by the SfM-MVS technology. Then, we extracted the features of glacier surface micro-topography (blue ice, crevasses, ice doline and melt-water). It's noteworthy that traces of melt-water and a large ice doline appeared on the surface of Dalk Glacier in December 2018. Finally, we concluded that surface micro-topographic features, observable in the UAV-derived models but unavailable on satellite images, may reveal hints for interactions between surface and beneath processes in regional polar glacier.
\end{abstract}

\section{INTRODUCTION}

Global climate warming has caused ice sheets and glaciers to shrink continuously almost worldwide (Dehecq et al., 2019; Pritchard et al., 2009), which contributes largely to the global sea level rise and may put millions of people living along the coasts at risk. The Antarctic ice sheet holds sufficient ice to raise world-wide sea level by more than $58 \mathrm{~m}$ if melted completely (Fretwell et al., 2013). Recent study shows that climate change is currently negatively impacting Antarctica (Rignot et al., 2019, Shen et al., 2019, Gardner et al., 2018). However, the interaction between climate and Antarctic ice sheet is not completely understood yet, such as glacier dynamic, mass balance, hydrology and iceberg calving. To some extent, the effects of these processes are possibly reflected in the surface micro-topographic features of glaciers, such as melt ponds, blue ice, crevasses and increased ice velocity (Qiao et al., 2020; Liang et al., 2019; Miles et al., 2018). Thus, analysis of glacier surface micro-topography is of significant importance for polar research.

There are two traditional methods for the glacier surface modelling: space-borne remote sensing and ground-based measurements. With large spatial coverage, the space-borne satellite remote sensing cannot usually provide high resolution details for glacier surface mapping (Howat., 2019; Bliakharskii et al., 2019). For the ground-based measurements, the harsh weather and expensive logistics have greatly limited the reachability to the remote glacier regions, especially in Antarctica (Li et al., 2019). Recently, Unmanned Aerial Vehicle (UAV) has been used more and more for data collection and surface modelling in remote sensing community (Bash et al., 2018; Yao et al., 2019; Florinsky et al., 2019a), making it possible to bridge the gap between sparse and discontinuous field observations and continuous but coarse resolution satellite remote sensing in polar regions (Bhardwaj et al., 2016).
To date, UAV has been employed in various aspects of cryosphere community, e.g., the topographic dataset (Benoit et al., 2019; Ewertowski et al., 2019) and the spatial distribution of ice cliffs and melt ponds on mountain glacier (Kraaijenbrink et al., 2016), supraglacial hydrological system of Greenland glaciers (Jouvet et al., 2018; Chudley et al., 2019), caving glacier monitoring in Greenland (Jouvet et al., 2019; Ryan et al., 2015), sea ice monitoring ( $\mathrm{Li}$ et al., 2019), modelling of topography and forelands in Antarctica (Dąbski et al., 2020; Bliakharskii et al., 2019; Florinsky et al., 2019b). To date, however, compared with Greenland and High Asia regions, more detailed analysis should be performed for glacier surface micro-topography study in Antarctica that could be conducted by UAV technology.

Nowadays, there are three types of UAV platforms: fixed-wing, multi-rotor, and hybrid platform. Fixed-wing UAV has a simple structure, with the advantage of natural gliding capabilities and longer flight durations at high speed, enabling large survey areas per flight (Bhardwaj et al., 2016). However, due to the requirements of take-off and landing sites, fixed wing platform is difficult to be employed in rugged mountainous terrain (Bhardwaj et al., 2016). Multi-rotor UAV can be easily controlled without prior experience, and take off and land in mountainous terrain with a limited operational range and low altitude flights. Hybrid platform combines the advantages of both fixed-wing and multi-copters (Jouvet et al., 2018), which can take off and land smoothly and accurately with long endurance and high speed. In this paper, a multi-rotor UAV is employed considering the specific terrain requirement, on-board sensors and budget.

This paper is as follows: Section 2 introduces the UAV platform and methods of image post-processing; Section 3 shows the results of micro-topography modelling; The conclusion and prospect are described in Section 4.

\footnotetext{
* Corresponding author
} 


\section{METHODS}

\subsection{UAV platform for photogrammetry with no Ground} Control

During the China's 35th Antarctic expedition period (CHINARE), we used a combined system of UAV, DJI Phantom 4 RTK version (https://www.dji.com/phantom-4-rtk), and a D-RTK mobile station for high-accuracy UAV photogrammetry without ground control points (GCPs), making use of the advantages of RTK.

DJI Phantom 4 RTK (Figure 1a), as a fully autonomous multirotor UAV, was equipped with a 20-megapixel CMOS sensor and batteries up to 30 min duration. In addition, an on-board Real-time kinematic (RTK) model is used for direct georeferencing of each image. The TimeSync system was designed to continually align the controller (Figure 1b), camera and RTK to make sure the positioning data was fixed to the optical centre of the lens. More importantly, D-RTK mobile station (Figure 1c) supplies the Phantom 4 RTK with real-time differential data for centimeter-level geo-positioning.

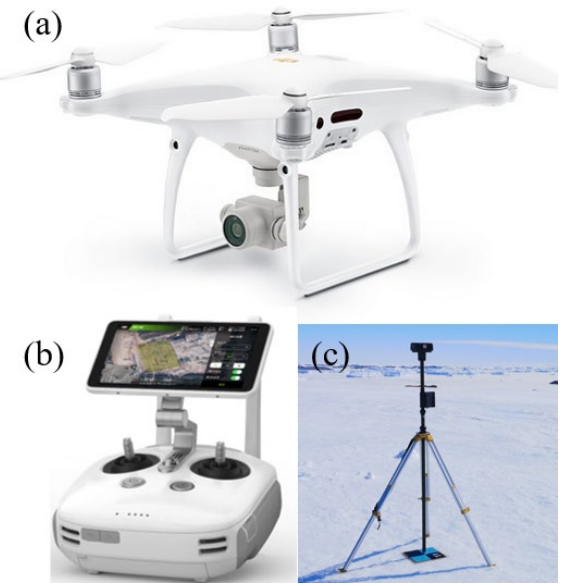

Figure 1. Combined system of DJI Phantom 4 RTK and D-RTK mobile station system. (a) UAV. (b) Remote controller. (c) DRTK mobile station.

\subsection{SfM-MVS photogrammetry}

In order to model local area of Antarctic ice sheet and glaciers, images obtained from each UAV survey were post-processed by structure-from-motion multi-view stereo technology (SfMMVS). We implemented the Photogrammetric software, Agisoft Metashape Professional Edition 1.5.5 (Agisoft LLC, 2019), due to the selectable modelling accuracy and editability of the point clouds in the intermediate steps. For each post-processing, four steps were performed in sequence. Firstly, feature recognition and matching algorithms were employed to find correspondences between images. Secondly, camera position and orientation of each image was aligned and a sparse point cloud was generated via bundle adjustment. Incorrectly positioned photos were removed after alignment. Thirdly, a dense point cloud was generated based on the estimated camera parameters. Some unreasonable points among dense points cloud were manually filtered. Finally, DEM and ortho-mosaic could be exported in an appropriate resolution based on the dense point cloud. For ortho-mosaic, colour calibration is necessary for the even brightness and white balance of the images over the data set (Agisoft LLC, 2019).

\subsection{Accuracy Assessment}

In order to assess the accuracy, the UAV photogrammetry without GCPs, an evaluation experiment was carried out at the Zhejiang Agriculture \&Forestry University, China in July 2019. UAV flights with three types of geo-positioning approaches were designed within an area of $2 \mathrm{~km}^{2}$ : D-RTK2 base station (unknown coordinates) without GCPs, D-RTK2 base station (known coordinates) without GCPs, and Network RTK without GCPs. The coordinates of evenly distributed GCPs were measured by GNSS RTK for the accuracy evaluation. The result showed a relative error within centimeter-level accuracy. We concluded that DJI Phantom 4 RTK achieved a relative mapping accuracy of centimetre-level and the absolute position may have an offset with meter-level due to the positioning of the D-RTK2 base station.

\section{RESULTS}

\subsection{Study area}

According the requirements of the 35th CHINARE, there were six UAV survey missions (Figure 2) performed in and near Larsemann Hills, a series of low rounded coastal hills along the south-eastern coast of the Prydz Bay, East Antarctica. Notably, Dalk Glacier, a small outlet glacier with approximate $8 \mathrm{~km}$ long and $3 \mathrm{~km}$ wide, is near the east of Larsemann Hills. Three yearround stations are located in this area: Zhongshan Station of China, Progress Station of Russia, and Bharati Station of India.

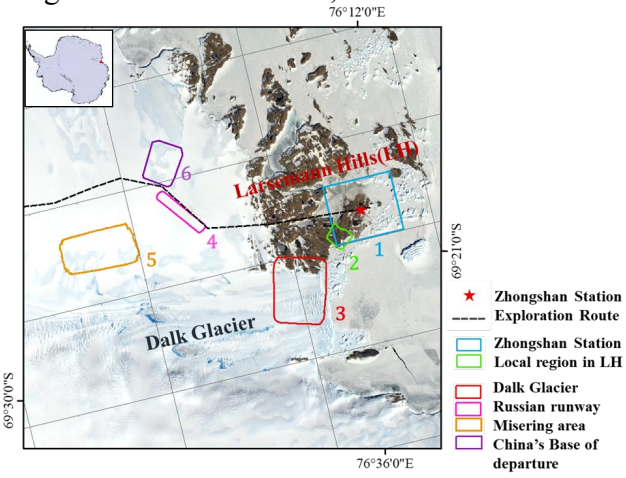

Figure 2. Location of the surveyed areas on the background of the Sentinel-2 image.

Among the six missions, the first and second areas used oblique aerial photogrammetry, aiming to obtain the Zhongshan Station and its surrounding area as much detail as possible to ensure the safety of the expedition. The remaining four areas used vertical aerial photogrammetry for the glacier surface micro-topography study. The third area is on the Dalk Glacier. The fourth and the fifth areas are on the inland of Antarctic ice sheet. Each UAV survey was performed under clear sunny weather with low wind speed. Flight time and other details of the UAV surveys are listed in Table 1.

Table 1. Details of the UAV surveys. Mission ID is shown in Figure 1.

\begin{tabular}{|c|c|c|c|c|}
\hline $\begin{array}{c}\text { Mission } \\
\text { ID }\end{array}$ & Date & $\begin{array}{c}\text { Area } \\
\left(\mathrm{km}^{2}\right)\end{array}$ & No. of images & $\begin{array}{c}\text { Flight height } \\
(\mathrm{m})\end{array}$ \\
\hline 1 & $2018 / 12 / 12$ & 5.74 & 1103 & 307 \\
2 & $2019 / 01 / 24$ & 0.53 & 608 & 127 \\
3 & $2019 / 01 / 14$ & 4.90 & 1332 & 236 \\
4 & $2018 / 12 / 12$ & 0.91 & 279 & 168 \\
5 & $2019 / 01 / 14$ & 3.98 & 447 & 319 \\
6 & $2019 / 01 / 15$ & 1.44 & 722 & 172 \\
\hline
\end{tabular}




\subsection{D modelling of Zhongshan Station}

Two models were generated based on the oblique photogrammetry of UAV survey: Zhongshan Station and a local region of Larsemann Hills. For Zhongshan Station, buildings, logistic facilities and surrounding geographical environment were investigated by the UAV-based photogrammetry (Figure 3a). The local region of Larsemann Hills is on the route of Chinese expedition team to the inland of Antarctica. This precise 3D model provided topography information in detail, which guaranteed the safety of scientific research (Figure 3b).

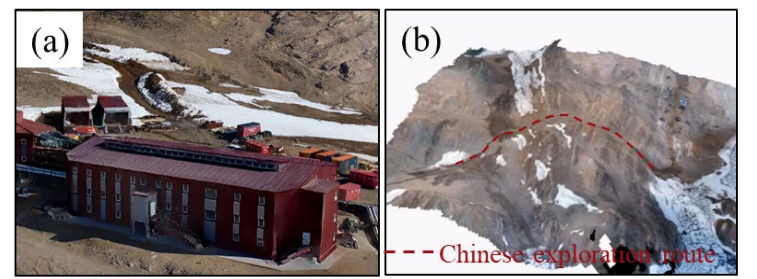

Figure 3. 3D modelling of Zhongshan Station. (a) Building of Zhangshan Station. (b) a local region of Larsemann Hills. The red dash line shows the exploration route of CHINARE.

\subsection{Micro-topography of Dalk Glacier terminus}

We generated high-resolution ortho-mosaic and DEM in the local area of Dalk Glacier terminus based on UAV survey and images post-processing. To further represent terrain information, the slope map was shown in Figure 4c. It could be found that the topography of the upstream and margin of glacier was relatively flat and the slope is small. In the middle of the glacier, massive crevasses appeared near the terminus, and the slope changed largely. It's worth noting that a strange rise of terrain modelling in the middle of the glacier terminus. The elevation on the red profile (Figure 4a) is shown in Figure 4d. Along the ice flow, the elevation gradually decreases from 120 to $90 \mathrm{~m}$. However, a rise about $10 \mathrm{~m}$ in height and $100 \mathrm{~m}$ in length appeared at the terminus of the glacier. At the same time, lots of crevasses appeared in this area, which may be correlated with the topography in the bottom of Dalk Glacier.
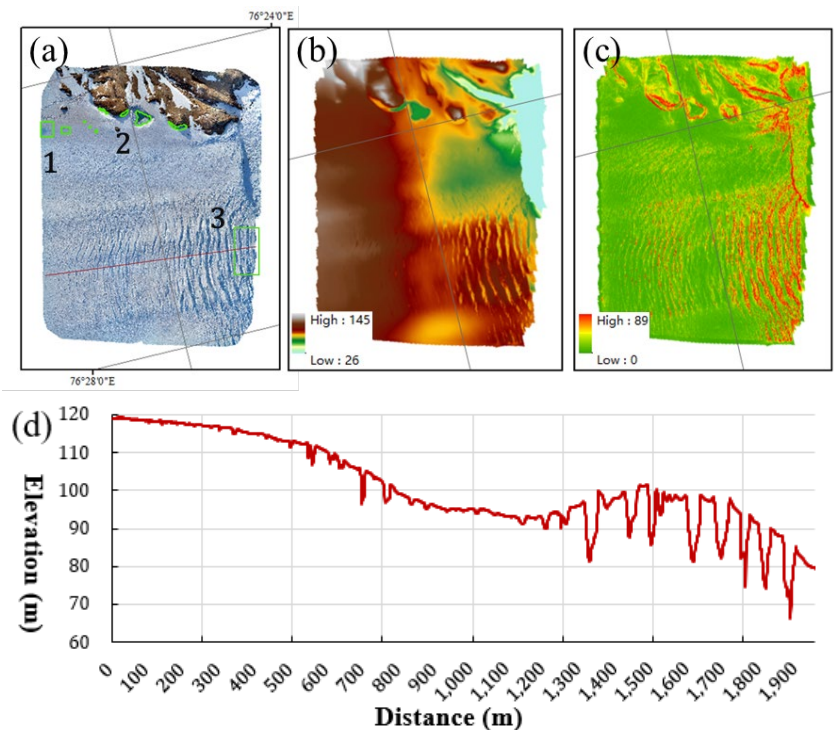

Figure 4. Modelling of Dalk Glacier terminus located in the red region showed in Fig.2. (a) Ortho-mosaics. (b) DEM. (c) Slope (d) Elevation profile of red line in (a).
Based on the above data, the surface micro-topography (ice melting, ice doline and crevasses) of glacier terminus could be observed in detail. We observed the melt-water running on the surface of the glacier (Figure 5a) with a sporadic distribution along the margin of Dalk Glacier near the Larsemann Hills. the largest area of the melt-water is about $10,000 \mathrm{~m}^{2}$. In addition, an ice doline (Figure 5b) with an area of $15,740 \mathrm{~m}^{2}$ and $25 \mathrm{~m}$ in depth was noticeable. However, it was not observed that any run-off appeared on the surface of the glacier. The melt-water and ice doline reflect the glacier hydrological system.

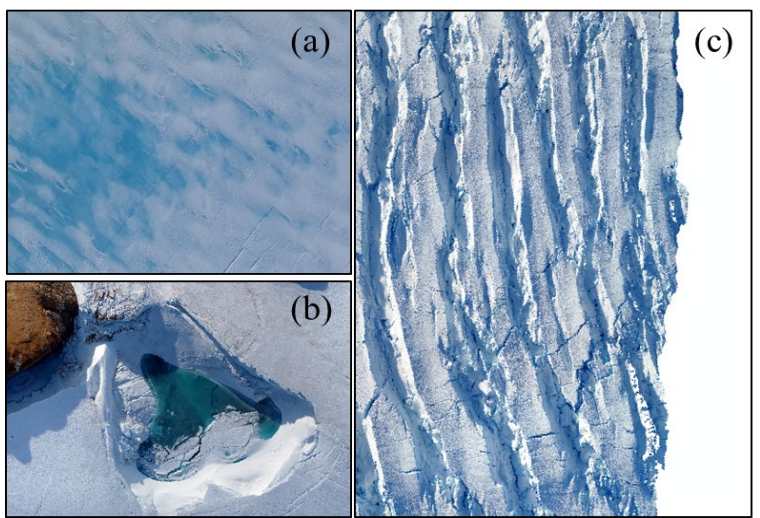

Figure 5. Micro-topography of Dalk Glacier terminus. (a) Ice melting. (b) Ice doline. (c) Crevasses.

\subsection{Micro-topography of inland ice sheet}

In the inland of Antarctica, blue ice and crevasses are important features for the study of surface micro-topography. Blue ice with a small area and extremely narrow crevasses is almost undetectable on the satellite images. We built the models of local region in inland ice sheet. Then, based on these models, blue ice with large area has been found (Figure 6b) and crevasses have been detected (Figure 6d).
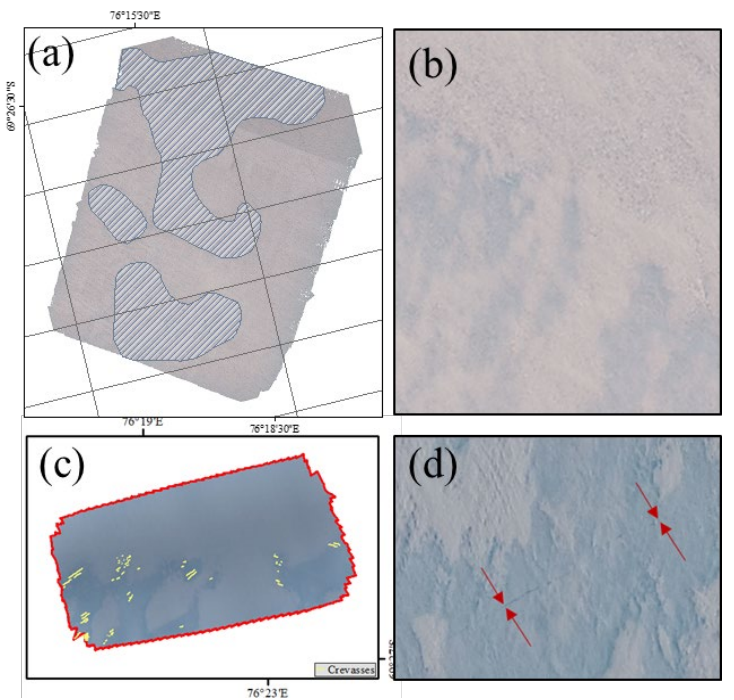

Figure 6. Micro-topography of inland ice sheet. (a) (b) blue ice. (c) (d)crevasses.

\section{CONCLUSIONS}

In this study, we generated ortho-mosaics and DEMs of glacier and ice sheet in East Antarctica with high precision and resolution, which shows the capabilities of UAV and UASbased photogrammetry for the modelling of micro-topography in difficult-access and dangerous areas under severe conditions 
of Antarctica. Based on this, the surface features of microtopography (such as blue ice, crevasses, ice doline and meltwater) were extracted and analyzed. We observed the traces of melt-water and a large ice doline along the side of Dalk Glacier, which may be linked with the supraglacial drainage networks. In addition, an unusual rise of terrain appeared in the middle of Dalk Glacier terminus accompanied by massive crevasses. We concluded that surface micro-topographic features, observable in the UAV-derived models but unavailable on satellite images, may reveal hints for interactions between surface and beneath processes in regional polar glacier.

Finally, in this paper, there are three prospects about the application of UAV in polar environment. Firstly, for the extremely harsh environment, UAV platform with longer working endurance is necessary in the future. Secondly, stronger positioning and navigation capability can provide better modeling of surface micro-topography. Thirdly, various UAV sensors (LiDAR, Multispectral sensor; Infrared sensor etc.) can gain more useful information to understand Antarctica.

\section{ACKNOWLEDGEMENTS (OPTIONAL)}

This work has been supported by the National Key Research \& Development Program of China (No. 2017YFA0603102), the National Science Foundation of China (41941006, 41771471), and the International Exchange Program for Graduate Students, Tongji University (No. 2020XKJC-009).

\section{REFERENCES}

Agisoft, L. L. C., 2018. Agisoft metashape user manual, Professional edition, Version 1.5. Agisoft LLC, St. Petersburg, Russia, from https://www. agisoft. com/pdf/metashapepro_1_5_en.pdf, accessed June, 2, 2019.

Bash, E. A., Moorman, B. J., \& Gunther, A., 2018. Detecting short-term surface melt on an arctic glacier using uav surveys. Remote Sensing, 10(10), 1547. doi: 10.3390/rs10101547.

Benoit, L., Gourdon, A., Vallat, R., Irarrazaval, I., Gravey, M., Lehmann, B., ... \& Mariethoz, G., 2019. A high-resolution image time series of the gorner glacier-swiss alps-derived from repeated unmanned aerial vehicle surveys. Earth System Science Data, 11(2), 579-588. 10.5194/essd-11-579-2019

Bhardwaj, A., Sam, L., Akanksha, Martín-Torres, F. J., \& Kumar, R., 2016. UAVs as remote sensing platform in glaciology: present applications and future prospects. Remote Sensing of Environment, 175, 196-204. doi:10.1016/j.rse.2015.12.029

Bliakharskii, D. P., Florinsky, I. V., \& Skrypitsyna, T. N., 2019. Modelling glacier topography in antarctica using unmanned aerial survey: assessment of opportunities. International Journal of Remote Sensing, 40(7), 2517-2541. doi:10.1080/01431161.2019.1584926

Chudley, T. R., Christoffersen, P., Doyle, S. H., Abellan, A., \& Snooke, N., 2019. High-accuracy uav photogrammetry of ice sheet dynamics with no ground control. The Cryosphere, 13(3), 955-968. doi:10.5194/tc-13-955-2019

Dehecq, A., Gourmelen, N., Gardner, A. S., Brun, F., Goldberg, D., Nienow, P. W., . . . Trouvé, E., 2018. Twenty-first century glacier slowdown driven by mass loss in high mountain asia.
Nature Geoscience, 12(1),22-27.doi:10.1038/s41561-018-02719

Ewertowski, M. W., Tomczyk, A. M., Evans, D. J., Roberts, D. H., \& Ewertowski, W., 2019. Operational framework for rapid, very-high resolution mapping of glacial geomorphology using low-cost unmanned aerial vehicles and structure-from-motion approach. Remote Sensing, 11(1), 65.doi: 10.3390/rs11010065

Florinsky, I. V., \& Bliakharskii, D. P., 2019a. Detection of crevasses by geomorphometric treatment of data from unmanned aerial surveys. Remote sensing letters, 10(4), 323332.doi: 10.1080/2150704X.2018.1552809

Florinsky, I. V., \& Bliakharskii, D. P., 2019b. The 2017 catastrophic subsidence in the dålk glacier, dast antarctica: unmanned aerial survey and terrain modelling. Remote sensing letters, 10(4), 333-342.doi: 10.1080/2150704X.2018.1552810

Fretwell, P., Pritchard, H. D., Vaughan, D. G., Bamber, J. L., Barrand, N. E., Bell, R., . . Z Zirizzotti, A., 2013. Bedmap2: improved ice bed, surface and thickness datasets for antarctica. The Cryosphere, 7(1), 375-393. doi:10.5194/tc-7-375-2013

Gardner, A. S., Moholdt, G., Scambos, T., Fahnstock, M., Ligtenberg, S., Van Den Broeke, M., \& Nilsson, J., 2018. Increased west antarctic and unchanged east antarctic ice discharge over the last 7 years. The Cryosphere, 12(2), 521-547. doi: $10.5194 /$ tc-12-521-2018

Qiao, G., Li, Y., Guo, S., Ye, W., 2020. Evolving instability of the scar inlet ice shelf based on sequential landsat images spanning 2005-2018. Remote Sensing, 12(1):36(2020). doi: $10.3390 /$ rs 12010036

Howat, I. M., Porter, C., Smith, B. E., Noh, M.-J., \& Morin, P., 2019. The reference elevation model of antarctica. The Cryosphere, 13(2), 665-674. doi:10.5194/tc-13-665-2019

Jouvet, G., Weidmann, Y., Kneib, M., Detert, M., Seguinot, J., Sakakibara, D., \& Sugiyama, S., 2018. Short-lived ice speed-up and plume water flow captured by a vtol uav give insights into subglacial hydrological system of Bowdoin Glacier. Remote Sensing of Environment, 217, 389-399. doi: 10.1016/j.rse.2018.08.027

Li, T., Zhang, B., Cheng, X., Westoby, M., Li, Z., Ma, C., . . . Li, X., 2019. Resolving fine-scale surface features on polar sea ice: a first assessment of uas photogrammetry without ground control. Remote Sensing, 11(7). doi:10.3390/rs11070784

Dąbski, M., Zmarz, M., Rodzewicz, M., Korczak-Abshire, M., Karsznia, I., Lach, K., Rachlewicz, G., \& Chwedorzewska, K., 2020. Mapping glacier forelands based on uav bvlos operation in antarctica. Remote Sensing, 12(4), 630. doi:10.3390/rs12040630

Miles, B. W. J., Stokes, C. R., \& Jamieson, S. S. R., 2018 Velocity increases at cook glacier, east antarctica, linked to ice shelf loss and a subglacial flood event. The Cryosphere, 12(10), 3123-3136. doi:10.5194/tc-12-3123-2018

Pritchard, H. D., Arthern, R. J., Vaughan, D. G., \& Edwards, L. A., 2009. Extensive dynamic thinning on the margins of the greenland and antarctic ice sheets. Nature, 461(7266), 971-975. doi:10.1038/nature08471 
Ryan, J. C., Hubbard, A. L., Box, J. E., Todd, J., Christoffersen, P., \& Carr, J. R., et al. 2015. UAV photogrammetry and structure from motion to assess calving dynamics at store glacier, a large outlet draining the greenland ice sheet. The Cryosphere, 9(1), 1-11. doi:10.5194/tc-9-1-2015

Shen, Q., Wang, H., Shum, C. K., Jiang, L., Hsu, H. T., \& Dong, J., 2018. Recent high-resolution Antarctic ice velocity maps reveal increased mass loss in wilkes land, east antarctica. Scientific reports, 8(1), 4477. doi:10.1038/s41598-018-22765-0

Yao, H., Qin, R., \& Chen, X., 2019. Unmanned aerial vehicle for remote sensing applications - a review. Remote Sensing, 11(12). doi:10.3390/rs11121443 